6. Brooks EM, Gonzalez M, Eden AR, O'Neal J, Sabo RT, Etz RS. What family physicians really think of maintenance of certification part ii activities. J Contin Educ Health Prof. 2017;37(4):223-229.

7. Puffer JC. A message from the president of the American Board of Family Medicine (ABFM). J Am Board Fam Med. 2016;29(6):815-816.

Ann Fam Med 2020;18:569. https://doi.org/10.1370/afm.2623.

\section{PEER-REVIEWED REPORTS IN MEDICAL EDUCATION RESEARCH (PRIMER) ACCEPTED FOR INCLUSION IN PUBMED CENTRAL}

STFM's online journal provides a dissemination opportunity for new researchers and small studies Peer-reviewed Reports in Medical Education Research (PRiMER), was accepted for full participation in PubMed Central (PMC), an archive of biomedical and life sciences journal literature at the US National Institutes of Health's National Library of Medicine.

"We are excited about passing this scientific and scholarly milestone. Indexing in PMC will greatly increase the visibility of PRiMER content, increase citations of our journal articles, and attract new authors," said Christopher Morley, PhD, PRiMER editor-in-chief.

PRiMER publishes small, rigorously designed original research briefs in medical education and health workforce policy, as well as medical student and resident research.

"PRIMER was developed to both introduce newer scholars to academic publishing in primary care medical education, as well as to provide an outlet for smaller studies by experienced researchers and educational scholars," said Dr Morley. "Having articles from PRiMER included in PubMed Central will expose the journal's content to wider audiences and increase its connection to other related PubMed content benefitting the authors, the journal, and the primary care research community as a whole."

In order to be accepted for full participation, PRiMER had to meet all scientific, editorial, and technical quality specifications that together establish the journal's adherence to the highest standards for peer review and scientific publishing. Participation guarantees a perpetual home for the full text of every PRiMER article, beyond the journal itself. It also provides indexing for PRiMER articles in PubMed, the world's top literature citation database for life science and medical research.
"We are thankful for Dr Morley's vision during the journal's creation and grateful to STFM leadership for their strong support. We also appreciate all the hard work of the PRiMER editorial team, editorial board, reviewers, and authors," said Traci Brazelton, CAE, STFM director of publications, who served as PRiMER managing publisher since its inception.

In July 2020, Sam Grammer took over the role of managing publisher for PRiMER. Mr Grammer brings more than 15 years of experience in academic publishing to the position, 9 of which were spent serving as a content specialist for the National Library of Medicine's Bookshelf project.

For more information about PRiMER, visit journals. stfm.org/PRiMER and follow the journal via Twitter at https://twitter.com/PRiMER_Journal

By Traci Brazelton, CAE STFM Director of Publications

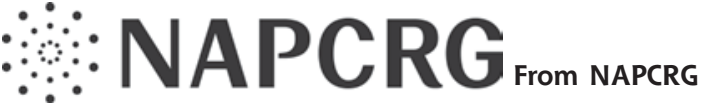

Ann Fam Med 2020;18:569-570. https://doi.org/10.1370/afm.2622.

\section{PBRN CONFERENCE HIGHLIGHTS Living Laboratories for Innovation and Dissemination/Implementation in Our Communities}

Most of the care for most of the patients most of the time is provided in community-based primary care practices. Generating new knowledge by conducting research in these practices and communities, and implementing research findings, is widely recognized as necessary to achieve better health for populations. It is the way to meet patients where they are to derive the insights that shape practice beyond textbooks. Practices and communities are like living laboratories.

This Living Laboratory theme served as the backdrop for the 2020 NAPCRG Practice-Based Research Network Conference, which brought together the energy of nearly 130 participants from the United States, Canada, and Japan and Australia in a first-ever virtual environment on August 13-14, 2020. Sponsored by AHRQ, the conference featured an array of ondemand presentations and an online poster hall, all of which have remained available to registered attendees for continued access. The ability to go back to presentations has enhanced continued learning.

Plenary speakers focused on fundamentals like implementation sustainability and implementation science:

- Implementation Sustainability, Dr Sharon Straus 